\title{
Design and Performance Analysis of Printed Bow-Tie Antenna for UHF (GOTV and STARTIMES) Reception in Nigeria
}

\author{
Adeniran A.O \\ Department of Physics, \\ University of Uyo, Uyo. \\ P.M.B 1017, Uyo, Akwa Ibom State, Nigeria
}

\begin{abstract}
Printed strip bow tie antenna is presented in order to achieve wide bandwidth, high gain and perfect smaller size suitable for indoor reception of UHF signal specifically for the newly introduced GOTV and STARCOM television (300-600MHz) television in Nigeria which uses Yagi antenna which is currently given the old environmental pictures to the Nigeria space. The simulated parameters shows that the bow-tie antenna has wider bandwidth ,higher gain ,lower front back ratio, lower cross polarization and smaller size of $1.5 \mathrm{~mm}$ which make it suitable for indoor wall decorator or perfectly incorporated in television panels.
\end{abstract}

\section{Keywords}

Microstrip Lines, Radiation Mechanism, Printed strip bow tie antenna

\section{INTRODUCTION}

In present scenario, the demand for wireless and compact technologies is increasing rapidly day by day where small size, light weight, ease installation are constraints. Printed strip antennas are widely used in phased array applications because they exhibit a very low profile, small size, light weight, low cost, high efficiency and easy method of fabrication and installation. Among the most widely used printed antenna in phased array systems are printed dipoles and Quasi Yagi antennas fed by coplanar strip line (CPS), which are usually used to yield end fire radiation pattern. However, their further use in specific systems is limited because of their relatively narrow bandwidth. In principal, wide bandwidth of microstrip patch antennas (MPAS) or bandwidth enhancement can be achieved by several efficient approaches [2], namely (i) increasing the substrate thickness (ii)optimizing impedance matching (iii)reducing the substrate effective permittivity or (iv)incorporating multiple resonance. Much effort has also been increasingly devoted to increasing the frequency agility of (MPAs) [2]. At the same time, MPAs need to be extremely small and compact to satisfy the severe size constraints of some critical applications such as mobile cellular handsets, card less phones and blue tooth devices. The miniaturization of normal MPA size (i) has typically been accomplished by loading; which can take various forms, such as (i)using a high permittivity substrates, (ii) Using shorting ports or shorting pins ,or (iii) modifying the basic patch shape[3].

\section{METHODS OF ANALYSIS}

There are three popular models for the analysis of microstrip antennas - viz transmission line model, cavity model and full wave model. The transmission line model is the simplest. It gives a good physical insight but is less accurate. The cavity model, which is used in this work, is quite complex but gives good physical insight and is more accurate. The full wave model is the most complex. It is very accurate in the design of finite and infinite arrays or stacked structures.

The quantity associated with radiated EM wave is the Poynting vector given as: [5]

$$
S=E \times H
$$

Where $\mathrm{S}$ is instantaneous Poynting vector, $\mathrm{E}$ is instantaneous electric field intensity and $\mathrm{H}$ is instantaneous magnetic field intensity. The complex fields $\mathrm{E}$ and $\mathrm{H}$ are related to their instantaneous counterparts by (6):

$$
\left.\begin{array}{l}
E(x, y, z, t)=\operatorname{Re}\left[E(x, y, z) e^{i w t}\right] \\
H(x, y, z, t)=\operatorname{Re}\left[H(x, y, z) e^{i w t}\right]
\end{array}\right\}
$$

Using and the identity $\operatorname{Re}\left(X c^{i w t}\right)=\frac{1}{2}\left(X e^{i w t}+X^{*} e^{i w t}\right)$ equation (1) can be rewritten as;

$$
S=\frac{1}{2} \operatorname{Re}\left[E \times H^{*}\right]+\frac{1}{2} \operatorname{Re}\left[E \times H e^{i w t}\right]
$$

Hence, the time average Poynting vector can be written as [5].

$$
S_{a v}=\frac{1}{2} \operatorname{Re}[E \times H] W m^{-2}
$$

\subsection{Radiation Mechanism}

Microstrip antennas are essentially suitably shaped discontinuities that are designed to radiate. The discontinuities represent abrupt changes in the microstrip line geometry. Discontinuities alter the electric and magnetic field distributions. As long as the physical dimensions and relative dielectric constant of the line remains constant, virtually no radiation occurs. However the discontinuity introduced by the rapid change in line width at the junction between the feed line and patch radiates. The other end of the patch where the metallization abruptly ends also radiates. When the field on a microstrip line encounters an abrupt change in width at the input to the patch electric fields spread out [3,2 and 6].

\subsection{Microstrip Lines}


A microstrip line consists of a single ground plane and a thin strip conductor on a low loss dielectric substrate [11] above the ground plate. Due to the absence of the top ground plate and the dielectric substrate above the strip, the electric field lines remain partially in the air and partially in the lower dielectric substrate. This makes the mode of propagation not pure TEM but what is called quasi-TEM. Due to the open structure and any presence in discontinuity, the microstrip line radiates electromagnetic energy. The use of thin and high dielectric materials reduces the radiation loss of the open structure where the fields are mostly confined inside the dielectric.

\section{ANTENNA DESIGN PRINCIPLES}

The designed antenna is Bow-Tie printed antenna. The first step of the design was the specification of a single microstrip patch antenna .The patch conductor can be assumed at any shape, but generally simple geometries are used, and this simplifies the analysis and performance prediction. Equilateral Triangular is considered here [9]. Its characteristics parameters are the length $\mathrm{L}$ which is equal to the width and as well as the third side with equal angles and the thickness $h$. To meet the initial design requirements (operating frequency $=$ between $300-600 \mathrm{MHz}$ ) various analytical approximate approaches may be used. Here, the calculations are based on the transmission line model [12]

\subsection{Design of Bow- Tie Strip Antenna}

For the design of bow-tie strip antenna the following parameters are needed:

$\mathrm{Er}=4.38 \quad, \quad$ height $(\mathrm{h})=1.6 \mathrm{~mm} \quad, \quad \mathrm{~W}=$ width ?, $\mathrm{Si}=2.93$.

The microstrip antenna is operated in basic $\mathrm{TM}^{10}$ mode and for this length of the patch should be less than where pie is the wavelength in dielectric medium.

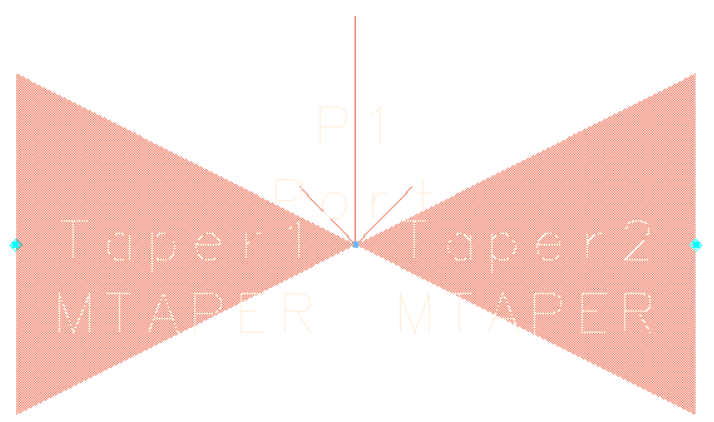

Figure 1: The Layout Picture for Bow- Tie Printed antenna on ADS2009

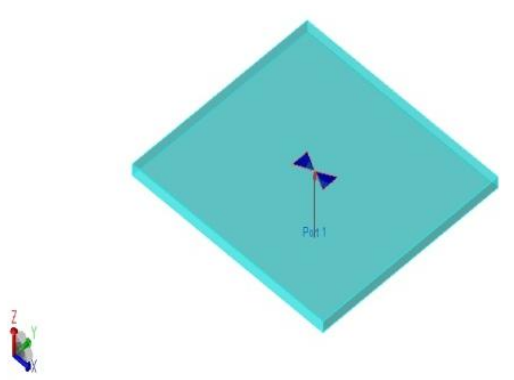

Figure2: The Layout Picture for Bow- Tie Printed on substrate on ADS2009
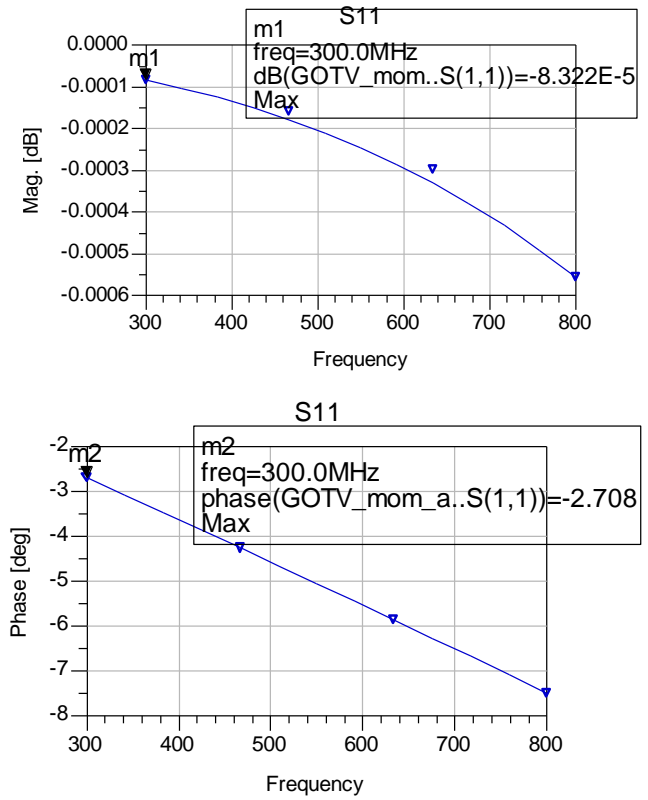

Figure 3: The graph for the input and output impedance for the Bow Tie Printed Antenna
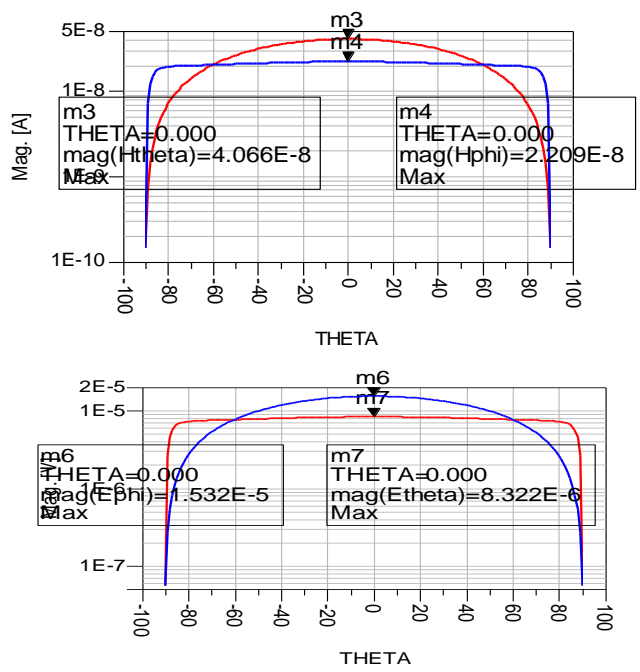

Figure 4: Magnetic (H) and Electric (E) for Bow- Tie Printed antenna

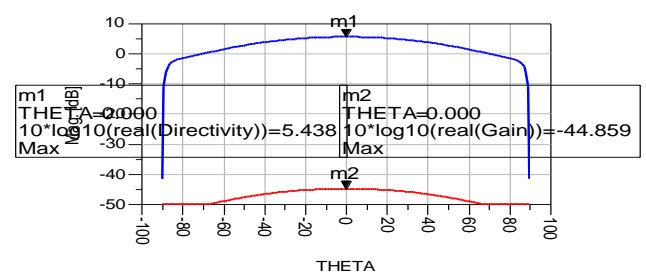




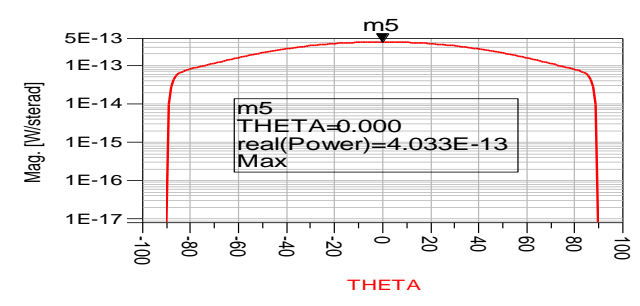

Figure 5: Directivity, Gain and Power for Bow- Tie Printed antenna

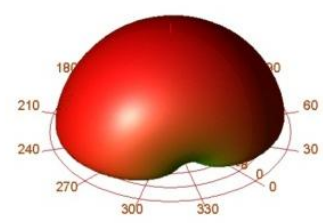

Figure 6: Radiation Pattern of Bow- Tie Printed antenna

Table 1: Antenna Parameters for Bow Tie Printed Patch Antenna

\begin{tabular}{|c|c|}
\hline Parameters & Values \\
\hline Gain(dB) & $-44.859 \mathrm{~dB}$ \\
\hline Directivity & $5.434 \mathrm{~dB}$ \\
\hline Return loss & \\
\hline Radiated power & $1.4502 \mathrm{E}-12$ \\
\hline E-Phi & -95.705 \\
\hline E-theta & 84.249 \\
\hline H-Phi & 84.488 \\
\hline H-theta & 84.248 \\
\hline
\end{tabular}

\section{CONCLUSION}

The design and performance analysis of printed Bow-Tie was simulated on ADS2000 platform and the parameters obtained shows the performance of the antenna at the frequency of 300$600 \mathrm{MHz}$, the directivity, Gain, Return Loss, Radiation in term of Magnetic and Electric as shown in Table 1.above are perfect and the obtained size for the antenna is printable on the televisions panel which make the gadget more smaller, compatible and perfect reception for GOTV and STARCOM (which operate at UHF band) television channels in Nigeria homes.

\section{REFERENCES}

[1] Agilent Software Inc. (2009): Advance Design System momentum simulator software.

[2] Adeniran A.O (2012) "Development of Scalene Triangular Microstrip Patch Antenna at 900MHz"

[3] Balanis C.A. (1997) Antenna Theory Analysis and Design Handbook. Second Edition, United States of America, John Willey \& Sons Inc. New York. pp.734.

[4] B. Banic, and Hajach,P.(2000): Design and Simulation of Properties of Log Periodic Dipole Antenna" In Radioelekrionika ,Brastslava,12-16,Sept,2000,pp108109.

[5] Bancroft .R. (2004) "Microstrip and Printed Antenna Design" Nobel Publishing, Chapter 2.

[6] Bhatia I. Bahl, P.R. Grag and Ittipiborn (2001) "Microstrip Antenna Design Handbook. Art2ech House: Boston.

[7] Greg and Yahya et al, (2004): Log Periodic Arrays .In the ARRL.Antenna Book [CD-ROM].The American Radio Relay League, Inc. Newington, CT06111-1494..

[8] James J.R. and Hall P.S. (1989). The Handbook of Microstrip Antennas. Peter Peregrinus Ltd., London on behalf of the IEEE, Vol. $1 \& 2$.

[9] Jackson D.R. (2007). Microstrip Antenna. Chapter 7 of Antenna Engineering Handbook, J.L. Volakis (ed.). McGraw Hill.

[10] Kraus J. D, Marhefka R. J, Muuk B. A, Lehto A, Vainikainen P, Newman E. H, and Walker C (2002): Antennas for All Applications. Third Edition, ISBN: 007-232103-2, McGraw-Hill USA. Pp. 237 - 245.

[11] Lo. Y.T, Solomon D. and Richards W.F (2007) "Theory and Experiment on Microstrip Antennas "IEEE Transaction on Antennas and Propagation. Vol. AP-27 Pp 137-149.

[12] Olaimat .M.M and Dib .N. I (2011) "A Study of 15-7590 degree Angles Triangular Patch Antenna “.Progress In Electromagnetic Research Letters. Vol. 2. Pp. 3 - 1.

[13] D. Nowwatzky, (1963): Logarithimisch periodische Antennen.Technische Milleilungen des RFZ, Jahrg.7/Heft2, June 1963, pp.77-80, and Jahrg, 7/Heft3, Sept.1963, pp.127-133. (http://home.tonline.de/home/Dieter.Nowatzky/doc.htm) 